\title{
Pulse wave analysis and diabetes mellitus. A systematic review
}

\author{
Jaromira Gajdova, David Karasek, Dominika Goldmannova, Ondrej Krystynik, Jan Schovanek, \\ Helena Vaverkova, Josef Zadrazil
}

Cardiovascular (CV) disease is the primary cause of death in diabetic patients and one of the explanations may be increased arterial stiffness. Arterial stiffness assessment using pulse wave analysis, is a predictive factor of CV events. The aim of this paper is to review the current knowledge of relations between diabetes mellitus and pulse wave analysis. A MEDLINE search was performed to retrieve both original and review articles addressing the relations and influences on arterial stiffness in diabetics. Pulse wave analysis is considered as a gold standard in CV risk evaluation for patients at risk, especially diabetics. Arterial stiffness assessment may be helpful for choosing more aggressive diagnostic and therapeutic strategies, particularly in younger patients to reduce the incidence of CV disease in these patients.

Key words: diabetes mellitus, arterial stiffness, pulse wave analysis

Received: November 21, 2016; Accepted with revision: May 25, 2017; Available online: June 5, 2017 https://doi.org/10.5507/bp.2017.028

Department of Internal Medicine III - Nephrology, Rheumatology and Endocrinology, University Hospital Olomouc and Faculty of Medicine and Dentistry, Palacky University Olomouc, Czech Republic

Corresponding author: Josef Zadrazil, e-mail:josef.zadrazil@fnol.cz

\section{INTRODUCTION}

Cardiovascular disease is the primary cause of death in patients with type 1 and type 2 diabetes $^{1}$. A number of studies showed increase in arterial stiffness in patients with type 1 (ref. $^{2}$ ) and type 2 diabetes $^{3,4}$. Increased arterial stiffness may be one important pathway linking diabetes to the reported increase in cardiovascular risk for this disease $^{5}$.

The arterial system has two main functions: to ensure an adequate blood flow to tissues and organs, i.e. "conduit function"; and "cushioning or dampening function". The efficiency of these functions depends on the stiffness, the geometry of the aorta and central arteries, and rigidity of successive arterial segments. Both functions are connected, since the efficient organ blood flow distribution is dependent on energy storage during diastole as arteries distend, i.e. their elastic properties, which, in return, buffer pressure and flow ${ }^{6}$. Arteries are exposed to shearing forces and a variety of local atherogenic factors that result in alteration of vascular structure and function characterized by an increase in luminal diameter and aortic stiffness and impact of reflected waves from the periphery ${ }^{7}$. The physiological role of the arterial system was greatly expanded by recognition of the central role of endothelial function in a variety of physiologic processes and also with the development of multiple parameters to evaluate arterial stiffness ${ }^{8}$. Many studies have already described the importance of arterial stiffness evaluation in cardiovascular risk assessment.

\section{ARTERIAL STIFFNESS}

Arterial stiffness may be assessed by a variety of methods, and has been linked to increase risk for the development of atherosclerosis, as well as being utilized as a prognostic marker beyond standard risk factor stratification $^{9}$. Arterial stiffness can be measured with non-invasive, reproducible, and relatively inexpensive techniques (for example pulse wave analysis by sphygmomanometer - Fig. 1). This method can be used to identify an increased cardiovascular risk, even before the first changes in the blood vessels detected by morphological imaging.

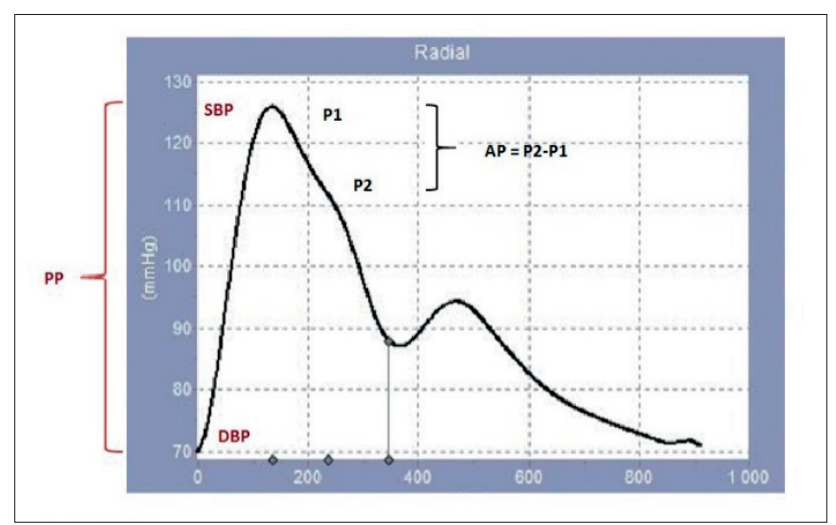

Fig. 1. Pulse wave analysis.

$\mathrm{P} 1$ = peak 1 (pressure at peak systolic flow), P2 = peak 2 (reflected wave), $\mathrm{SBP}=$ systolic blood pressure, $\mathrm{DBP}=$ diastolic blood pressure, $\mathrm{PP}=$ pulse pressure, $\mathrm{AP}=$ augmentation pressure. 
Table 1. Hemodynamic parameters related to arterial stiffness.

\begin{tabular}{|c|c|c|c|}
\hline $\begin{array}{l}\text { Hemodynamic } \\
\text { parameters } \\
\text { (abbreviations/units) }\end{array}$ & Calculation details & Definition & Comments \\
\hline $\begin{array}{l}\text { Pulse pressure } \\
(\mathrm{PP}, \mathrm{mmHg})\end{array}$ & SBP - DBP & $\begin{array}{l}\text { The difference between systolic } \\
\text { (SBP) and diastolic blood pressure } \\
\text { (DBP). }\end{array}$ & $\begin{array}{l}\text { Pulse pressure measured in brachial } \\
\text { artery may be up to } 20-50 \% \text { greater } \\
\text { than in aorta }{ }^{92} \text {. }\end{array}$ \\
\hline $\begin{array}{l}\text { Augmentation } \\
\text { pressure } \\
(\mathrm{AP}, \mathrm{mmHg})\end{array}$ & $\mathrm{P} 2-\mathrm{P} 1$ & $\begin{array}{l}\text { The difference between second (P2) } \\
\text { and first (P1) systolic peaks. }\end{array}$ & $\begin{array}{l}\text { P1 corresponds to pressure at the } \\
\text { peak systolic flow. } \\
\text { P2 corresponds to the peak of } \\
\text { reflected wave. }\end{array}$ \\
\hline $\begin{array}{l}\text { Augmentation index } \\
(\mathrm{AIx}, \%)\end{array}$ & $\frac{\mathrm{P} 2-\mathrm{P} 1}{\mathrm{PP}} \times 100$ & $\begin{array}{l}\text { AIx is derived from the difference } \\
\text { between second (P2) and first (P1) } \\
\text { systolic peaks of arterial pulse wave } \\
\text { expressed as a percentage of pulse } \\
\text { pressure }^{5} \text {. }\end{array}$ & $\begin{array}{l}\text { A calculation measures the height } \\
\text { of the reflected wave relative to the } \\
\text { incident wave }{ }^{8} \text {. }\end{array}$ \\
\hline $\begin{array}{l}\text { AIx normalized for } \\
\text { heart rate of } 75 \text { bpm } \\
\text { (AIx@75, \%) }\end{array}$ & $\frac{\mathrm{P} 2-\mathrm{P} 1}{\mathrm{PP}} \times 100 / 75$ & $\begin{array}{l}\text { AIx normalized for heart rate of } 75 \\
\text { bpm. }\end{array}$ & Increase pulse rate lowers the $\mathrm{Aix}^{93}$. \\
\hline $\begin{array}{l}\text { Pulse wave velocity } \\
(\mathrm{PWV}, \mathrm{m} / \mathrm{s})\end{array}$ & $\frac{L}{\Delta \mathrm{t}}$ & $\begin{array}{l}\text { Pressure wave velocity travelling } \\
\text { along an arterial segment, deter- } \\
\text { mined by the length }(\mathrm{L}) \text { of studied } \\
\text { arterial segment divided by pres- } \\
\text { sure wave travel time from arterial } \\
\text { location A to location B within the } \\
\text { segment }(\Delta \mathrm{t})^{5} \text {. }\end{array}$ & $\begin{array}{l}\text { The gold standard for assessment } \\
\text { arterial stiffness, because of its } \\
\text { reproducibility and reliability }{ }^{25} \text {. }\end{array}$ \\
\hline
\end{tabular}

Several devices for pulse wave analysis are commercially available and extensively used worldwide. The technique involves use of an applanation tonometer to record radial pulse wave ${ }^{10}$, simultaneously the central blood pressure and pulse wave velocity. These methods use various indices to describe the arterial stiffness (Table 1). The most commonly used parameters are central (aortal) blood pressure, the augmentation index (AIx) and pulse wave velocity (PWV), which may be used for assessment of cardiovascular $(\mathrm{CV})$ risk in patients with diabetes mellitus.

\section{Reflective wave phenomenon}

Central blood pressure (pressure measured in elastic type arteries, e.g. aorta) is a better predictor of cardiovascular events than peripheral blood pressure (pressure measured in the muscular artery) (ref. ${ }^{10}$ ). Central arterial waveforms are influenced by the reflective wave phenomenon. The systolic waveform leaves the aortic root and travels to the periphery, where smaller arterioles act as a multiple reflection point. The resulting "reflective" wave is generated and returns to central arteries ${ }^{11,12}$, where it contributes to the characteristic aortic pressure wave morphology, which can be further quantified ${ }^{8}$. The speed of an advancing wave is termed pulse wave velocity ${ }^{13}$. With age, a combination of increased reflective capacity at peripheral sites and faster PWV within stiffened vessels causes premature augmentation of the systolic waveform ${ }^{14}$. In stiff arteries the reflected pressure wave returns during early systole, forming an early systolic peak on waveform analysis ${ }^{5,15,16}$. This explains the differences between the brachial and aortic pressure waveforms, which may be as high as $20 \mathrm{mmHg}$ (ref. ${ }^{14}$ ) (Fig. 2). The central pressure waveform is important to determine left ventricular workload, which is relatively independent of the brachial pressure. This difference diminishes with age, and most people over 65 years of age have similar central and peripheral blood pressures ${ }^{10}$.

\section{Arterial stiffness measurement limitation}

Measurement of arterial stiffness is a very useful method for cardiovascular risk evaluation. However, markers of arterial stiffness are interrelated with a variety of hemodynamic parameters, such as heart rate, systolic and diastolic blood pressure as well as pulse pressure. The interrelationship of these various parameters is difficult to separate on clinical grounds, which renders studies of the individual impact of various interventions on the clinical outcome rather difficult as various therapies have overlapping outcomes on modification of stiffness and hemodynamics ${ }^{8}$.

There are some caveats regarding assessment of arterial stiffness given the heterogeneity of used methods across the studies measuring aortic PWV (ref. ${ }^{17}$ ). For example, there is no universal consensus on which distance should be introduced in the PWV equation. Some studies adjust for heart rate determining both $\mathrm{CV}$ outcome and PWV, others adjust for body mass index and weight because these relate to both PWV and CV events. Aortic 

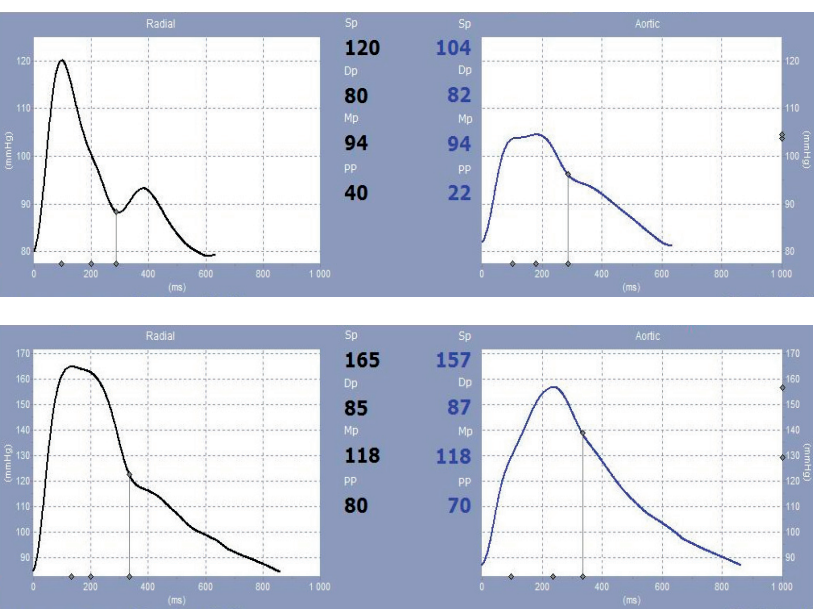

Fig. 2. Pulse wave analysis in radial artery (peripheral) and aorta (central).

As aortic and arterial stiffness increase, transmission velocity of both forward and reflected waves increases, causing quicker arrival of the reflected wave to central aorta and augment systolic pressure. Therefore, augmentation of central aortic pressure wave is a manifestation of early wave reflection and is the boost pressure forming the first systolic shoulder to the systolic pressure peak ${ }^{12}$.

a) Healthy compliant arteries - Comparison of systolic peripheral (left, radial artery $120 / 80 \mathrm{mmHg}$ ) and central pressure (right, aorta $104 / 82 \mathrm{mmHg}$ ), difference observed in healthy individuals. b) Stiffen arteries - Minimal difference between systolic peripheral (left, radial artery $165 / 85 \mathrm{mmHg}$ ) and central pressure (right, aorta $157 / 87 \mathrm{mmHg}$ ).

PWV is currently the best documented and most widely used marker of arterial stiffness. Standardization of its measurement would also facilitate comparability and validation of other emerging stiffness indexes ${ }^{17}$.

\section{ARTERIAL STIFFNESS AND DIABETES MELLITUS TYPE 2}

A large body of evidence supports the concept of increased arterial stiffness in type 2 diabetes ${ }^{3,18}$. Central blood pressure is a significant predictor of cardiovascular events in the elderly, as well as in patients with a large variety of diseases, such as coronary artery disease, renal disease and diabetes ${ }^{19}$.

Pulse wave velocity, pulse pressure and augmentation index are significantly increased in diabetic patients when adjusted for age, gender, and heart rate in mean aortic pressure $^{4,8}$. This is an early phenomenon that occurs in the impaired glucose metabolism state (i.e. impaired fasting glucose and/or impaired glucose tolerance) ( ref. $^{3}$ ) Increased arterial stiffness was observed in newly diagnosed, never treated diabetic patients without any cardiovascular complications; aortic PWV was significantly higher in diabetic and impaired glucose tolerance patients when compared to euglycemic persons ${ }^{20}$. These findings support the so-called "common soil" or "ticking clock" hypothesis, which suggests that macrovascular disease associated with type 2 diabetes already begins in the pre-

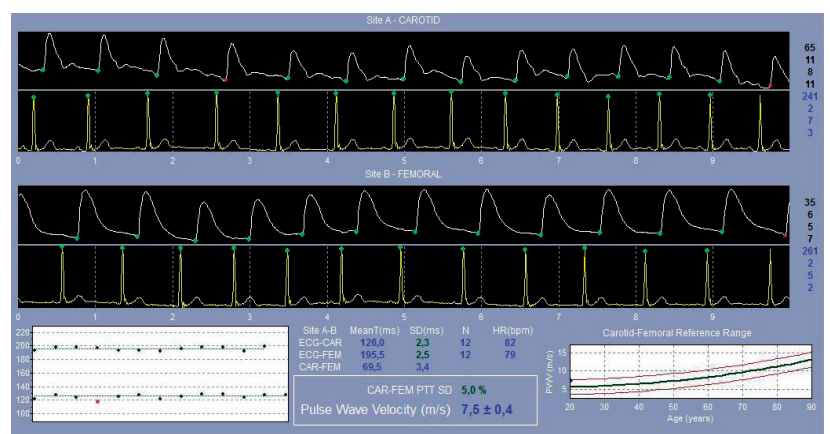

Fig. 3. Pulse wave velocity - carotid-femoral.

PWV analysis utilizes system that calculates pulse wave propagation velocity between two sites, commonly the carotid and femoral pulses ${ }^{96}$. To ensure of simultaneity pulse wave propagation an $\mathrm{R}$ wave on the electrocardiograph can be used to calculate the wave transit time.

diabetic state ${ }^{5}$. An increase in aortic stiffness, as measured by aortic PWV, is an independent predictor of mortality in diabetic patients ${ }^{21}$. Data from the 10 year follow-up study showed that brachial systolic pressure and aortic PWV was greater in people with diabetes and glucose intolerance than in non-diabetics. In the presence of diabetes and glucose intolerance, the mortality risk doubled ${ }^{22}$. Furthermore, increased arterial stiffness, PWV and AIx have been reported in the offspring of newly diagnosed never treated type 2 diabetic and impaired glucose toleration parents, revealing early manifestations of preclinical vasculopathy and a potentially increased cardiovascular risk in the future ${ }^{23}$. Yet some clinical studies demonstrated that the presence of diabetes alters the augmentation index, and consequently it is not reliable to measure it in diabetic patients ${ }^{24}$. PWV is a gold standard for the assessment of arterial stiffness because of its reproducibility and reliability, in addition to its association with cardiovascular risk in different populations ${ }^{25}$ (Fig. 3). The PWV threshold was determined as $10 \mathrm{~m} / \mathrm{s}$ (ref. ${ }^{26,27}$ ). However, in the 2016 European guidelines on cardiovascular disease prevention in clinical practice the PWV threshold of $12 \mathrm{~m} / \mathrm{s}$ was used as a conservative estimate of aortic function significant alterations in middle-aged hypertensive patients $^{28}$. Aortic PWV may be a more useful technique for measuring changes in arterial stiffness over a long period of time, whereas wave reflection techniques may be especially useful for measuring short-term changes secondary to therapeutic interventions ${ }^{26}$.

\section{Pathobiology of increased arterial stiffness in diabetes}

The first age-related changes in the vessel wall can already be seen at around 20 years of age ${ }^{29}$. The degree of aortic stiffening is multifactorial and is mediated by a variety of structural and functional alterations that progressively occur over time. With age and the influence of other external or internal factors (hyperglycaemia, dyslipidemia, smoking and obesity), the arterial system loses compliance and progressive stiffening occurs, altering arterial media, which is formed by vascular smooth muscle and a variable degree of elastic tissue. Physiologic vessel disten- 
Table 2. Influence of drugs or drugs groups on arterial stiffness.

\begin{tabular}{llcc}
\hline Drug groups & Drug class/drug & Effect on arterial stiffness & Ref. \\
\hline Insulin & Insulin & $+/-$ & $8,31,78$ \\
Peroral antidiabetic drugs & Metformin & + & $81,82,87$ \\
& Sulfonylurea & $+/-$ & $85,89,90$ \\
& Glitazones & $+/-$ & $80,83,84$ \\
& DPP - 4 inhibitors & $+/-$ & 86,87 \\
& GLP - 1 analogs & - & 88 \\
& SGLT 2 inhibitors & + & $89-91$ \\
Antihypertensive drugs & Acrabose & + & 84 \\
& Angiotensin-converting-enzyme inhibitors (ACEIs) & + & $69,94,95$ \\
& Angiotensin II receptor blockers (ARBs) & + & + \\
& Calcium channel blockers (CCBs) & - & \\
& Diuretics & & \\
\hline
\end{tabular}

+ the drug or drug group improves arterial stiffness, - the drug or drug group does not improve arterial stiffness, $+/-$ conflicting effect (the drug or drug group is distributed between improving arterial stiffness or not.

sibility is adversely affected by a progressive reduction of elastic tissue coupled with enhanced collagen deposition and vascular calcification ${ }^{8}$, therefore the arteries are less pliable and become wider and longer ${ }^{10}$. The most typical clinical consequence of arterial stiffening is a steep pressure volume relationship, e.g. increased systolic blood pressure (SBP) during ventricular ejection and decreased diastolic blood pressure (DBP) during diastolic runoff, resulting in high pulse pressure (PP) $\left(\right.$ ref. $\left.^{30}\right)$.

\section{Etiology of an increased arterial stiffness in diabetes}

Vascular wall elasticity is influenced by many external and internal factors (e.g. age, blood pressure, glycaemia, gender, pulse, smoking, exercising or height) that may confound the data. Reduction of elasticity leads to an increased cardiovascular risk. There are a number of potential mechanisms by which diabetes might affect arterial stiffness, but the exact mechanism for increased arterial stiffness still remains to be explained ${ }^{15}$.

\section{Role of insulin resistance}

Insulin resistance usually precedes development of type 2 diabetes and is often accompanied by a cluster of other risk factors characteristic for the metabolic syndrome 5 .

Insulin, at physiological concentrations, has acute vasodilatory effects that lead to increased arterial distensibility; however, these beneficial effects are blunted in insulin-resistant states $^{31}$. In a large population-based study, insulin concentrations (a more indirect measure of insulin sensitivity) were associated with higher carotid artery stiffness, and this association was also stronger in women than in men $^{32}$. Increased insulin stimulates the sympathetic nervous system, resulting in increased heart rate and blood pressure. In addition, insulin may cause hypertrophy of the vascular wall, resulting in an increase in the number and size of monocytes, increased collagen, and proliferation of smooth muscle cells ${ }^{33}$. In diabetic patients, inverse associations were observed between clamp-measured insulin sensitivity and arterial stiffness in carotid and femoral arteries ${ }^{34}$. Insulin resistance contrib- utes to increased arterial stiffness independently of blood pressure in type 2 diabetic patients but also in apparently healthy individuals ${ }^{10}$.

\section{Advanced glycation end products}

One of the main mechanisms by which diabetes affects arterial stiffness is the formation of advanced glycation end products (AGEs) in the arterial wall, causing crosslinking of collagen molecules, and potentially leading to the loss of collagen elasticity and a subsequent increase in arterial stiffness ${ }^{35}$. Indeed, AGEs were associated with a greater arterial wall stiffness in diabetic patients ${ }^{36}$, and cross-link breakers were demonstrated to decrease arterial stiffness in humans ${ }^{37}$. Chronic hyperglycaemia and hyperinsulinemia also increase local activity of the reninangiotensin-aldosterone system and expression of the angiotensin type I receptor in vascular tissue, promoting the development of arterial wall hypertrophy and fibrosis ${ }^{38}$.

\section{Inflammatory process}

Interrelated low-grade inflammation and endothelial dysfunction, may also explain, at least in part, the increase in arterial stiffness related to diabetes and metabolic syndrome $^{39}$. Endothelial dysfunction may lead to functional stiffening of large arteries as reduced availability of nitric oxide and increased activity of vasoconstrictors such as endothelin-1, affect vascular smooth muscle cell tone $\mathrm{e}^{40}$. Endothelial dysfunction may lead to smooth muscle cell proliferation and increased synthesis of structural proteins such as collagen. Low-grade inflammation impairs endothelial function, which may therefore result in increased arterial stiffness ${ }^{41}$.

\section{C-reactive protein}

One of the most commonly used inflammation markers is a high sensitivity C-reactive protein (hs-CRP), which is not only a marker of cardiovascular risk, but may itself function as a proatherogenic molecule ${ }^{42}$. In healthy individuals, after controlling for age and heart rate, both aortic and brachial PWV were associated with an elevation of the hs-CRP, while AIx was contrarily not elevated ${ }^{43}$. Some 
studies identified hs-CRP as an independent predictor of cardiovascular events, hypertension, and diabetes ${ }^{44}$. One study showed that the association of hs-CRP to arterial stiffness parameters differs between men and women. Hs-CRP positively correlated with carotid IMT (carotid intima-media thickness), and peripheral AIx in men, and negatively correlated to central AIx in women. For each unit increase in hs-CRP, PWV would increase by 0.07 $\mathrm{m} / \mathrm{s}$ in men and by $0.08 \mathrm{~m} / \mathrm{s}$ in women, while central AIx would decrease by 2.5 units in women ${ }^{45}$. These studies showed that an inflammatory process can affect arterial stiffness directly without influencing the wave reflection sites $^{26}$. However, prospective data to test the mediating role of endothelial dysfunction and/or inflammation on the metabolic syndrome and diabetes-related arterial stiffening are still lacking ${ }^{2}$.

\section{Oxidative stress}

Oxidative stress plays an important role in the process of atherogenesis, and may be another cause of higher cardiovascular disease occurrence in diabetic patients. Thereby, some studies assessed the effect of oxidative stress, and correlated it with inflammation, arterial stiffness and other cardiovascular risk factors. A study by Lessiani et al. showed that exercise training was significantly associated with markers of lipid peroxidation; also PWV was significantly reduced after this exercise. They concluded that regular physical exercise may be a natural antioxidant strategy, lowering oxidant stress and thereby the degree of arterial stiffness ${ }^{46}$.

\section{DIABETES MELLITUS COMPLICATIONS}

Diabetes has many complications associated with arterial stiffness. There are many studies trying to evaluate the relations between increased arterial stiffness and type 2 diabetes mellitus, particularly the relationships with microvascular or macrovascular complications.

\section{Microvascular complications}

In type 2 diabetic patients, increased central arterial stiffness is associated with the presence of microvascular complications independently of other established determinants of aortic stiffness. In the Rio de Janeiro Type 2 Diabetes Cohort Study, retinopathy and nephropathy, aside from age, heart rate, $24 \mathrm{~h}$ pulse pressure, diabetes duration, dyslipidemia and the number of antihypertensive drugs in use, were independently associated with aortic PWV (ref. ${ }^{47}$ ). In a study by Theilade, the same results were found in patients with diabetes type 1 . Arterial stiffness increased with the presence and duration of type 1 diabetes. Furthermore, PWV increased in all investigated diabetes complications (cardiovascular, renal, retinal, and autonomic disease) independently of other risk factors ${ }^{48}$.

\section{Neuropathy}

Studies on type 2 diabetic patients showed that diabetic neuropathy is significantly associated with age, duration, glycated hemoglobin (HbA1c), systolic blood pressure, diastolic blood pressure, PP, hypertension, retinopathy, urinary albumin excretion rate, nephropathy, PWV and IMT. PWV and PP were significantly associated with neuropathy independently of conventional cardiovascular risk factors. Multifactorial intervention to inhibit progression of the atherosclerotic process may slow progression of neuropathy ${ }^{49}$. The Rio de Janeiro Type 2 Diabetes Cohort Study clinically assessed the presence of diabetic polyneuropathy at the baseline and after a median follow-up of 6.2 years. Increased aortic stiffness (carotid-femoral PWV $>10 \mathrm{~m} / \mathrm{s}$ ) at baseline predicted future development or progression of peripheral neuropathy, independently of diabetic metabolic control, suggesting a physiopathological link between macrovascular and microvascular abnormalities in type 2 diabetes $^{47}$.

Cardiovascular autonomic neuropathy in patients with diabetes mellitus type 2 was evaluated in the study by Sergienko. The subclinical stage of cardiovascular autonomic neuropathy was characterized by an increased pulse wave velocity in the aorta, and aortic and brachial augmentation indexes throughout the day and night. Daily PWV values and the ambulatory arterial stiffness index in patients with functional-organic cardiovascular autonomic neuropathy were significantly higher when compared to groups with subclinical and functional stages of cardiovascular autonomic neuropathy ${ }^{50}$.

\section{Retinopathy}

Association between arterial stiffness and diabetic retinopathy was evaluated in the Ogawa studies. PWV, duration of diabetes, systolic blood pressure and glycated hemoglobin level were all significantly higher in patients with diabetic retinopathy ${ }^{51}$. On the other hand, association between AIx and diabetic retinopathy was not statistically significant. The clinical significance appears to be different between PWV and AIx in patients with diabetes $^{52}$. PWV might be a marker of vascular injury caused by chronic hyperglycaemia, rather than a marker of retinopathy ${ }^{51}$.

Nephropathy and chronic kidney disease

Aortic stiffness is increased in patients suffering from chronic kidney disease (CKD) at any stage and also in transplant recipients. Its impact on general and cardiovascular risk prognosis is widely accepted. The glomerular microcirculation may be exposed to damaging pulsatile pressures in the presence of increased aortic stiffness, as reflected in elevated central PP. Consequences of increased arterial stiffness and affected renal microcirculation are albuminuria and progressive nephropathy ${ }^{53}$.

Carotid-femoral PWV measurements improve the prediction of $\mathrm{CV}$ risk in CKD patients beyond the traditional and renal $\mathrm{CV}$ risk factors. However, conflicting results were published about the relationship between aortic stiffness and estimated glomerular filtration rate (eGFR) within the CKD population ${ }^{54}$. A recent meta-analysis of the usefulness of central pressure measurements for predicting $\mathrm{CV}$ disease events concluded that the augmentation index provided independent $\mathrm{CV}$ diseases predictive utility when modelled together with traditional blood pressure ${ }^{17}$. 
Aortic PWV is significantly higher in patients with chronic kidney disease and a mild-to-moderate decreased glomerular filtration rate than in hypertensive and normotensive patients without chronic kidney disease ${ }^{55}$. A systematic review and meta-analysis indicated that aortic PWV possess a better ability to predict adverse outcomes in subjects with higher baseline $\mathrm{CV}$ risk (patients with coronary artery disease, renal disease, hypertension, or diabetes) than in subjects with presumably lower risk (general population).

Although there was no difference in risk prediction/ estimates in relation to age in hypertensive patients or in general population subjects, there was a better predictive ability of arterial stiffness for clinical events in younger end stage renal disease (ESRD) patients. The explanation for the latter may include a "selection" phenomenon, with ESRD patients reaching older age being less vulnerable to the harmful effects of arterial stiffening, but the present data may underestimate the discriminative ability of stiffness in some populations, and clearly there is a need for further studies ${ }^{17}$. The impact of large artery stiffening and remodelling on CKD progression is also still a matter of research. Concomitant exposure to other CV risk factors, including diabetes, seems to play a major role in the association between aortic stiffness and eGFR (ref. ${ }^{54}$ ). Aortic PWV and AIx are independent predictors of cardiovascular (and all-cause) mortality in ESRD patients on hemodialysis, independent of other known factors affecting the outcome, and for each increase in AIx of $10 \%$, the risk of cardiovascular and all-cause mortality is increased by around $50 \%\left(\right.$ ref. $\left.^{56}\right)$.

Kidney transplantations improve patient CV prognosis, but its impact on arterial stiffness is still controversial. Donor age, living kidney donation and mean blood pressure appear to be the main determinants of improvement in aortic stiffness after kidney transplantation ${ }^{54}$.

\section{Macrovascular complications}

Increased arterial stiffness is associated with the presence of $\mathrm{CV}$ risk factors and atherosclerotic disease ${ }^{57,58}$. Importantly, a number of studies examined the ability of arterial stiffness evaluation to predict the risk of fatal and nonfatal CV events (myocardial infarction, stroke, revascularization, stroke, aortic syndromes) and total mortality. Arterial elastic properties are increasingly used for risk stratification purposes in several populations, and recently, the European Society of Hypertension / European Society of Cardiology guidelines for the management of arterial hypertension suggested the measurement of aortic pulse wave velocity, a gold standard of aortic stiffness assessment, as a tool to examine subclinical organ damage $^{59}$. Assessment of arterial stiffness including central blood pressure measurement is a strong predictor of major cardiovascular events, independent of traditional risk factors ${ }^{8}$.

Meta-analysis of 17 longitudinal studies evaluating aortic PWV in 15,877 patients for a mean of 7.7 years showed that aortic stiffness expressed as aortic PWV was a strong predictor of future CV events and all-cause mortality. Some analysis indicated that aortic PWV has a better ability to predict adverse outcomes in subjects with higher baseline $\mathrm{CV}$ risk (patients with coronary artery disease, renal disease, hypertension, or diabetes) than in subjects with presumably lower CV risk (general population) $\left(\right.$ ref. $\left.^{26,60}\right)$.

\section{DIABETES MELLITUS AND COMORBIDITIES}

Patients with diabetes suffer from many comorbidities potentially influencing arterial stiffness, including obesity, hypertension, hypercholesterolemia, CKD or non-alcoholic fatty liver disease (NAFDL). We have to consider these factors when assessing arterial stiffness.

\section{Metabolic syndrome and obesity}

Many studies attempted to explain increased arterial stiffness in the metabolic syndrome. It is important to stress that this association is not only related to higher blood pressure; the central obesity and increased fasting glucose levels were also independent traits consistently associated with arterial stiffness, whereas dyslipidemia was less so. These are the traits that are most often observed in a combination that is associated with the greatest mortality risk ${ }^{61}$. Apart from the induction of insulin resistance ${ }^{62}$, an increased influx of free fatty acids was proposed as a possible link between central obesity and PWV (ref. ${ }^{63}$ ). Free fatty acids may contribute to vascular stiffness by increasing adrenergic reactivity, vascular tone, and blood pressure $^{64}$.

An increase in arterial stiffness was associated with obesity both in adults and children, independently of blood pressure, ethnicity and age ${ }^{65}$. Aortic PWV was associated with visceral adiposity, as measured by abdominal tomography and waist circumference in healthy elderly persons by the Aging and Body Composition Study, and these finding were independent of age, gender and blood pressure ${ }^{33}$. Some studies showed a positive correlation of waist circumference (WC) and waist/height ratio (WHtR) to PWV and carotid IMT (ref. ${ }^{66,67}$ ). In Arners' study the visceral adipocyte volume, not number, was strongly and positively correlated with PWV, explaining 20\% of the inter-individual variations in this parameter. Although a causal relationship was not established, the study showed that visceral fat cell volume may explain the well-known correlation between central fat mass, arterial stiffness and cardiovascular risk, at least in severely/morbidly obese subjects ${ }^{68}$.

\section{Hypertension}

Arterial stiffness is an independent predictor of CV morbidity and mortality in patients with hypertension, as well as a potential therapeutic target ${ }^{69}$. A large number of studies reports the association between hypertension and arterial stiffness (SBP, PP, AIx and PWV) (ref. ${ }^{16,70-72}$ ). Profound analysis of these factors is beyond the scope of this article.

\section{Hyperlipidemia}

High cholesterol levels were reported to be associated with a high central pressure and increased aortic 
stiffness $^{73}$, despite similar brachial pressures. Levels of plasma triacylglycerides are also related to measures of arterial stiffness. In the study with 1,447 subjects after a median follow-up interval of 4.8 years, multiple linear regression analysis revealed that triacylglycerides were independently associated with carotid-femoral PWV and carotid-radial PWV (ref. ${ }^{74}$ ).

\section{Non-alcoholic fatty liver disease}

Increasing data suggess that non-alcoholic fatty liver disease (NAFLD) may be linked to atherosclerotic vascular disease independently of other established cardiovascular risk factors. It has been shown that increased aortic stiffness predicts cardiovascular morbidity and mortality in several clinical settings, including diabetes type 2 , generally associated with advanced stages of NAFLD. Recently published studies reported a strong association between NAFLD and increased arterial stiffness, suggesting a possible link in the pathogenesis of atherosclerosis and NAFLD. A 7-year longitudinal study showed that patients who presented with either an increase in aortic stiffness or persistently high values had significantly higher mean liver stiffness than those who either had decreased aortic stiffness or persisted with normal carotid-femoral PWV values, after adjustments for anthropometric-demographic and clinical laboratory covariates ${ }^{75}$.

\section{EFFECT OF THE THERAPY ON ARTERIAL STIFFNESS}

Multiple pharmacologic agents have been proposed to modify arterial stiffness ${ }^{8}$. A large number of publications have reported improvements in arterial stiffness and central blood pressure after pharmacological interventions (Table 2). These include medication used to treat hypertension, high cholesterol, diabetes and also nonpharmacological interventions such as the cessation of cigarette smoking, dietary changes and physical exercise ${ }^{76,77}$.

\section{Antihypertensive drugs}

A review focused on the effect of antihypertensive drugs on arterial hemodynamic demonstrated that newer antihypertensive drugs (angiotensin-converting-enzyme inhibitors (ACEIs), angiotensin II receptor blockers (ARBs) and calcium channel blockers (CCBs)) efficiently reduce both arterial stiffness and central blood pressure. Their common features are likely arterial dilating capacity and the ability to reduce pressure wave reflections, such as expressed by the augmentation index ${ }^{69}$. These topics are extensively discussed in other reviews and exceed the focus of this article.

\section{Insulin}

Insulin therapy shows conflicting effects on arterial stiffness. Physiological concentrations of insulin lead to increased arterial distensibility, but with insulin resistance these positive effects are reduced ${ }^{31}$. Insulin treatment decreases arterial stiffness in a type 2 diabetic through improvement of postprandial hyperglycemia ${ }^{78}$. Nevertheless utilization of insulin therapy was demonstrated to be associated with more severe aortic stiffness ${ }^{8}$.

\section{Peroral antidiabetic drugs}

There are not many prospective controlled studies focused on arterial stiffness and the effect of oral antidiabetics. There are many confounding factors influencing arterial stiffness (e.g. blood pressure, age, dyslipidemia, smoking and medications) which may affect the data. Another limitation of studies is their interpretation due to using different techniques for assessment of arterial stiffness, as well as many parameters (e.g. AIx, central blood pressure and PWV) for describing arterial stiffness.

The available studies with metformin, the first choice treatment for diabetes type 2 , are especially conflicting. Metformin is often used as a drug comparator but the results are controversial. In a study by Stakos et al. the long term cardiovascular effects of oral antidiabetic agents in non-diabetic patients with insulin resistance was evaluated. This study showed increase in PWV after treatment with metformin for 24 months, although fasting serum glucose, insulin, $\mathrm{C}$ peptide and blood pressure did not change $^{79}$. In a study by Kiycy et al. patients with type 2 diabetes did not show a significant decrease in vascular stiffness $^{80}$. However, metformin treatment was associated with decrease in arterial stiffness in patients with NAFLD (ref. ${ }^{81}$ ) and polycystic ovary syndrome ${ }^{82}$. In a placebo, double-blind, crossover study on young women with polycystic ovary syndrome (without a history of known hypertension, hyperlipidemia, or diabetes) metformin improved AIx, aortic PWV, brachial and central blood pressure. Metformin also reduced weight, waist circumference, and triglycerides but did not affect other metabolic measures $^{82}$.

Glitazone treatment improves arterial stiffness in patients with type 2 diabetes. A study by Kiyicy et al. showed that rosiglitazone monotherapy has a favourable effect on arterial stiffness (small artery elasticity index) compared with metformin monotherapy independent of glycemic control. DBP and mean arterial pressure was decreased in rosiglitazone group when compared with baseline values although there was no difference when compared to the metformin group, however SBP did not change ${ }^{80}$. Long-term study has demonstrated that treatment with pioglitazone improved arterial stiffness index, compared to insulin, sulfonylurea and diet/exercise therapy. There was improvement of arterial stiffness despite the same glycemic control between the pioglitazone group and sulfonylurea group. In the pioglitazone group, compared to other groups, fewer patients used antihypertensive medications to achieve normal peripheral blood pressure. This finding could reflect independence of pioglitazone on antihypertensive therapies ${ }^{83}$.

Acarbose treatment reduces the risk of cardiovascular disease by altering the arterial stiffness in the postprandial hyperglycaemic status in patients with type 2 diabetes. In this study a significant reduction in cardio-ankle vascular index (a parameter of arterial stiffness) was shown, although the changes in blood pressure and heart rate were not significant ${ }^{84}$. 
Nagayama et al. showed glimepiride improves the cardio-ankle vascular index compared with glibenclamide in patients with type 2 diabetes $^{85}$.

Dipeptidyl peptidase - 4 inhibitors (DDP-4) improve arterial stiffness, blood pressure, lipid profile and inflammation parameters in patients with type 2 diabetes mellitus. Duvnjak et al. in an uncontrolled open-label, parallel-arm 12 week study demonstrated a significant reduction in total serum cholesterol, AIx@75, periferal and central systolic blood pressure with sitagliptin and vildagliptin treatment in patients with type 2 diabetes. The PWV also decreased but this did not reach statistical significance ${ }^{86}$. Yet in a Zografou et al. study, vildagliptin in combination with metformin had no effect on arterial stiffness (carotid-femoral PWV), blood pressure, body mass index, or lipid profile when compared with metformin alone ${ }^{87}$.

In patients with type 2 diabetes, well controlled with metformin monotherapy, addition of liraglutide, a glucagon like peptide - 1 analog, for 12 weeks, did not show improvement in arterial stiffness ${ }^{88}$.

Sodium glucose co-transport (SGLT-2) inhibitors significantly reduce systolic and diastolic blood pressure in patients with type 2 diabetes mellitus compared with placebo or active controls (glimepiride, glipizide, sitagliptin). A post hoc analysis of data from five randomized controlled trials showed that empagliflozin significantly reduced risk factors of arterial stiffness such as double product, mean arterial pressure, and pulse pressure compared with placebo ${ }^{89,90}$. SGLT-2 inhibitors may improve endothelial function or the vascular architecture (collagen, elastin, advance glycation products) and other components of connective tissue that participate in the process of arterial stiffening ${ }^{91}$.

\section{CONCLUSION}

Arterial stiffness is increased in patients with diabetes mellitus and could be one important pathway linking diabetes to increase in CV risk ${ }^{5}$. Regardless of its limitations in arterial stiffness assessment, and interference with many parameters, pulse wave analysis is considered a gold standard in cardiovascular risk evaluation in high risk patients, especially diabetics. Despite the institution of novel therapeutic interventions, the high residual prevalence of cardiovascular events urges us to identify novel risk factors. More aggressive diagnostic and therapeutic strategies might be appropriate, particularly in younger patients with increased arterial stiffness ${ }^{8}$. Therefore, development of new therapies for patients with diabetes allows us to individualize their treatment and choose the best strategy to decrease CV risk. Additionally, modification of arterial stiffness provides a potential therapeutic target to reduce cardiovascular events in diabetic patients.

\section{Search strategy and selection criteria}

We searched Medline and Medscape for both original and review articles published after 1991. Additional information was retrieved from references in relevant ar- ticles. The search strategy consisted of both controlled vocabulary, such as the National Library of Medicine's MeSH (Medical Subject Headings), and keywords. Search terms included arterial stiffness, diabetes mellitus, pulse wave analysis and pulse wave velocity. The search was performed during December 2015 and November 2016. Studies published in English and Czech on the association between arterial stiffness and diabetes mellitus were reviewed.

\section{ABBREVIATION}

ACEIs, Angiotensin-converting-enzyme inhibitors; AGEs, Advanced glycation end products; AIx, Augmentation index; AIx@75, Augmentation index standardized for $75 \mathrm{bpm}$; AP, Augmentation pressure; ARBs, Angiotensin II receptor blockers; CCBs, Calcium channel blockers; CKD, Chronic kidney disease; CV, Cardiovascular; DDP-4, Dipeptidyl peptidase - 4; DBP, Diastolic blood pressure; eGRF, Estimated glomerular filtration rate; ESRD, End stage renal disease; HbA1c, Glycated hemoglobin; hsCRP, High sensitive C-reactive protein; IMT, Intima-media thickness; MeSH, Medical Subject Headings; NAFDL, Non-alcoholic fatty liver disease; PP, Pulse pressure; PWV, Pulse wave velocity; SBP, Systolic blood pressure; SGLT-2, Sodium glucose co-transport; WC, Waist circumference; WHtR, Waist/ height ratio.

Acknowledgement: This review was financially supported by grant no. IGA LF_2017_015 (Faculty of Medicine and Dentistry, Palacky University Olomouc, Czech Republic) and by the Ministry of Health, Czech Republic DRO (FNOL 00098892) - 87-62.

Author contributions: JG: literature search and manuscript writing; DK, OK, DG, JZ, JS: literature search and critical reading; all authors: manuscript revision.

Conflict of interest statement: The authors declare there are no conflicts of interest regarding the publication of this article.

\section{REFERENCES}

1. Fowler MJ. Microvascular and Macrovascular Complications of Diabetes. Clin Diabetes 2008;26(2):77-82.

2. Stehouwer CDA, Henry RMA, Ferreira I. Lane HA, Smith JC, Davies JS. Noninvasive assessment of preclinical atherosclerosis. Vasc Health Risk Manag 2006;2(1):19-30. Diabetologia 2008;51(4):52739. doi:10.1007/s00125-007-0918-3

3. Schram MT, Henry RMA, van Dijk RAJM, Kostense PJ, Dekker JM, Nijpels G, Heine RJ, Bouter LM, Westerhof N, Stehouwer CDA. Increased central artery stiffness in impaired glucose metabolism and type 2 diabetes: the Hoorn Study. Hypertension 2004;43(2):17681. doi:10.1161/01.HYP.0000111829.46090.92

4. Mohan V. Macrovascular component of diabetes atherosclerosis and insulin (CUPS-18). J Assoc Physicians India 2007;55 Suppl:13-18.

5. Stehouwer CDA, Henry RMA, Ferreira I. Arterial stiffness in diabetes and the metabolic syndrome: a pathway to cardiovascular disease. Diabetologia 2008;51(4):527-39. doi:10.1007/s00125-007-0918-3

6. Boutouyrie P, Fliser D, Goldsmith D, Covic A, Wiecek A, Ortiz A, Martinez-Castelao A, Lindholm B, Massy ZA, Suleymanlar G, Sicari R, 
Gargani L, Parati G, Mallamaci F, Zoccali C, London GM. Assessment of arterial stiffness for clinical and epidemiological studies: methodological considerations for validation and entry into the European Renal and Cardiovascular Medicine registry. Nephrol Dial Transplant 2014;29(2):232-9. doi:10.1093/ndt/gft309

7. O'Rourke MF, Nichols WW. Aortic diameter, aortic stiffness, and wave reflection increase with age and isolated systolic hypertension. Hypertension 2005;45(4):652-8. doi:10.1161/01. HYP.0000153793.84859.b8

8. Liao J, Farmer J. Arterial stiffness as a risk factor for coronary artery disease. Current atherosclerosis reports 2014;16(2):387. doi:10.1007/ s11883-013-0387-8

9. London GM, Cohn JN. Prognostic application of arterial stiffness: task forces. Am J Hypertens 2002;15(8):754-8.

10. Lane HA, Smith JC, Davies JS. Noninvasive assessment of preclinical atherosclerosis. Vasc Health Risk Manag 2006;2(1):19-30. doi:10.2147/vhrm.2006.2.1.19

11. O'Rourke MF, Kelly RP. Wave reflection in the systemic circulation and its implications in ventricular function. J Hypertens 1993;11(4):32737.

12. O'Rourke MF, Mancia G. Arterial stiffness. J Hypertens 1999;17(1):1-4

13. Lehmann ED, Riley WA, Clarkson P, Gosling RG. Non-invasive assessment of cardiovascular disease in diabetes mellitus. Lancet (London, England) 1997;350 Suppl:SI14-9.

14. Pauca AL, Wallenhaupt SL, Kon ND, Tucker WY. Does radial artery pressure accurately reflect aortic pressure? Chest 1992;102(4):1193-8.

15. Greenwald SE. Ageing of the conduit arteries. J Pathol 2007;211(2):157-72. doi:10.1002/path.2101

16. Widimsky jr, J. Widimsky J. Hypertenze 4. Rozšířené a přepracované vydání Praha:Triton; 2014

17. Vlachopoulos C, Aznaouridis K, Stefanadis C. Prediction of Cardiovascular Events and All-Cause Mortality With Arterial Stiffness. J Am Coll Cardiol 2010;55(13):1318-27. doi:10.1016/j. jacc.2009.10.061

18. Taniwaki H, Kawagishi T, Emoto M, Shoji T, Kanda H, Maekawa K, Nishizawa Y, Morri H. Correlation between the intima-media thickness of the carotid artery and aortic pulse-wave velocity in patients with type 2 diabetes. Vessel wall properties in type 2 diabetes. Diabetes Care 1999;22(0149-5992(Print)):1851-7.

19. Pini R, Cavallini MC, Palmieri V, Marchionni N, Di Bari M, Devereux RB, Masotti G, Roman MJ. Central but not brachial blood pressure predicts cardiovascular events in an unselected geriatric population: the ICARe Dicomano Study. J Am Coll Cardiol 2008;51(25):2432-9. doi:10.1016/j.jacc.2008.03.031

20. Rahman S, Ismail AA-S, Ismail SB, Naing NN, Rahman ARA. Early manifestation of macrovasculopathy in newly diagnosed never treated type II diabetic patients with no traditional CVD risk factors. Diabetes Res Clin Pract 2008;80(2):253-8. doi:10.1016/j.diabres.2007.12.010

21. Cruickshank K, Riste L, Anderson SG, Wright JS, Dunn G, Gosling RG. Aortic pulse-wave velocity and its relationship to mortality in diabetes and glucose intolerance: an integrated index of vascular function? Circulation 2002;106(16):2085-90.

22. Schram MT, Kostense PJ, Van Dijk RA, Dekker JM, Nijpels G, Bouter LM, Heine RJ, Stehouwer CD. Diabetes, pulse pressure and cardiovascular mortality: the Hoorn Study. J Hypertens 2002;20(9):1743-51

23. SphygmoCor and Diabetes. [manual for device Sphygmocor] Available from: http://www.atcormedical.com.

24. Lacy PS, O'Brien DG, Stanley AG, Dewar MM, Swales PPR, Williams B. Increased pulse wave velocity is not associated with elevated augmentation index in patients with diabetes. J Hypertens 2004;22(10):1937-44

25. Engelen L, Ferreira I, Stehouwer CD, Boutouyrie P, Laurent $S$. Reference intervals for common carotid intima-media thickness measured with echotracking: relation with risk factors. Eur Heart 2013:34(30):2368-80. doi:10.1093/eurheartj/ehs380

26. Franklin SS. Beyond blood pressure: Arterial stiffness as a new biomarker of cardiovascular disease. J Am Soc Hypertens 2008;2(3):140 51. doi:10.1016/j.jash.2007.09.002

27. Filipovsky J, Widimsky J Jr., Spinar J. Summary of 2013 ESH/ESC Guidelines for the management of arterial hypertension: Prepared by the Czech Society of Hypertension/Czech Society of Cardiology. Cor et Vasa 2014;56(6):e494-e518. doi:10.1016/j.crvasa.2014.07.007

28. Piepoli MF, Hoes AW, Agewall S, Albus C, Brotons C, Catapano AL, Cooney MT, Corrà U, Cosyns B, Deaton C, Graham I, Hall MS, Hobbs FD, Løchen ML, Löllgen H, Marques-Vidal P, Perk J, Prescott
E, Redon J, Richter DJ, Sattar N, Smulders Y, Tiberi M, van der Worp HB, van Dis I, Verschuren WM; Authors/Task Force Members. 2016 European Guidelines on cardiovascular disease prevention in clinical practice: The Sixth Joint Task Force of the European Society of Cardiology and Other Societies on Cardiovascular Disease Prevention in Clinical Practice (constituted by representatives of 10 societies and by invited experts)Developed with the special contribution of the European Association for Cardiovascular Prevention \& Rehabilitation (EACPR). Eur Heart J. 2016;37(29):231581 doi:10.1093/eurheartj/ehw106.

29. Safar ME, Levy Bl, Struijker-Boudier H. Current perspectives on arterial stiffness and pulse pressure in hypertension and cardiovascular diseases. Circulation 2003;107(22):2864-9. doi:10.1161/01. CIR.0000069826.36125.B4

30. London GM, Pannier B. Arterial functions: how to interpret the complex physiology. Nephrol Dial Transplant 2010;25(12):3815-23. doi:10.1093/ndt/gfa614

31. Yki-Jarvinen $\mathrm{H}$, Westerbacka J. Insulin resistance, arterial stiffness and wave reflection. Adv Cardiol 2007;44:252-60. doi:10.1159/000096746

32. Salomaa V, Riley W, Kark JD, Nardo C, Folsom AR. Non-insulindependent diabetes mellitus and fasting glucose and insulin concentrations are associated with arterial stiffness indexes. The ARIC Study. Atherosclerosis Risk in Communities Study. Circulation 1995;91(5):1432-43.

33. Sutton-Tyrrell K, Newman A, Simonsick EM, Havlik R, Pahor M, Lakatta E, Spurgeon H, Vaitkevicius P. Aortic stiffness is associated with visceral adiposity in older adults enrolled in the study of health, aging, and body composition. Hypertension 2001;38(3):429-33.

34. van Dijk RAJM, Bakker SJL, Scheffer PG, Heine RJ, Stehouwer CDA. Associations of metabolic variables with arterial stiffness in type 2 diabetes mellitus: focus on insulin sensitivity and postprandial triglyceridaemia. Eur J Clin Invest 2003;33(4):307-15.

35. Aronson D. Cross-linking of glycated collagen in the pathogenesis of arterial and myocardial stiffening of aging and diabetes. J Hypertens 2003;21(1):3-12. doi:10.1097/01.hjh.0000042892.24999.92

36. Schram MT, Schalkwijk CG, Bootsma AH, Fuller JH, Chaturvedi $\mathrm{N}$, Stehouwer CDA. Advanced glycation end products are associated with pulse pressure in type 1 diabetes: the EURODIAB Prospective Complications Study. Hypertension 2005;46(1):232-7. doi:10.1161/01.HYP.0000164574.60279.ba

37. Kass DA, Shapiro EP, Kawaguchi M, Capriotti AR, Scuteri A, DeGroof RC, Lakatta EG. Improved arterial compliance by a novel advanced glycation end-product crosslink breaker. Circulation 2001;104(13):1464-70.

38. Creager MA, LuscherTF, Cosentino F, Beckman JA. Diabetes and vascular disease: pathophysiology, clinical consequences, and medical therapy: Part I. Circulation 2003;108(12):1527-32. doi:10.1161/01. CIR.0000091257.27563.32

39. Ferreira I, Boreham CA, Twisk JWR, Gallagher AM, Young IS, Murray LJ, Stehouwer CDA. Clustering of metabolic syndrome risk factors and arterial stiffness in young adults: the Northern Ireland Young Hearts Project. J Hypertens 2007;25(5):1009-20. doi:10.1097/ HJH.0b013e3280a94e76

40. McEniery CM, Qasem A, Schmitt M, Avolio AP, Cockcroft JR, Wilkinson IB. Endothelin-1 regulates arterial pulse wave velocity in vivo. J Am Coll Cardiol 2003;42(11):1975-81.

41. Hingorani AD, Cross, J, Kharbanda RK, Mullen MJ, Bhagat K, Taylor $M$, Donald AE, Palacios M, Griffin GE, Deanfield JE, MacAllister RJ, Vallance P. Acute systemic inflammation impairs endothelium-dependent dilatation in humans. Circulation 2000;102(9):994-9.

42. Szmitko PE, Wang C-H, Weisel RD, de Almeida JR, Anderson TJ, Verma S. New markers of inflammation and endothelial cell activation: Part I. Circulation 2003;108(16):1917-23. doi:10.1161/01. CIR.0000089190.95415.9F

43. Yasmin, McEniery CM, Wallace S, Mackenzie IS, Cockcroft JR, Wilkinson IB. C-reactive protein is associated with arterial stiffness in apparently healthy individuals. Arterioscler Thromb Vasc Biol 2004;24(5):969-74. doi:10.1161/01.ATV.zhq0504.0173

44. Ridker PM, Rifai N, Rose L, Buring JE, Cook NR. Comparison of C-reactive protein and low-density lipoprotein cholesterol levels in the prediction of first cardiovascular events. N Engl J Med 2002;347(20):1557-65. doi:10.1056/NEJMoa021993

45. Gomez-Marcos MA, Recio-Rodriguez Jl, Patino-Alonso MC, AgudoConde C, Gomez-Sanchez L, Rodriguez-Sanchez M, MartinezVizcaino V, Garcia-Ortiz L. Relationships between high-sensitive 
C-reactive protein and markers of arterial stiffness in hypertensive patients. Differences by sex. BMC Cardiovasc Disord 2012;12(1):37. doi:http://dx.doi.org/10.1186/1471-2261-12-37

46. Lessiani G, Santilli F, Boccatonda A, lodice P, Liani R, Tripaldi R, Saggini R, Davi G. Arterial stiffness and sedentary lifestyle: Role of oxidative stress. Vascul Pharmacol 2016;79:1-5. doi:10.1016/j.vph.2015.05.017

47. Cardoso CRL, Moran CBM, Marinho FS, Ferreira MT, Salles GF. Increased aortic stiffness predicts future development and progression of peripheral neuropathy in patients with type 2 diabetes: the Rio de Janeiro Type 2 Diabetes Cohort Study. Diabetologia 2015;58(9):2161-8. doi:10.1007/s00125-015-3658-9

48. Theilade S, Lajer M, Persson F, Joergensen C, Rossing P. Arterial stiffness is associated with cardiovascular, renal, retinal, and autonomic disease in type 1 diabetes. Diabetes Care 2013;36(3):715-21. doi:10.2337/dc12-0850

49. Yokoyama H, Yokota Y, Tada J, Kanno S. Diabetic neuropathy is closely associated with arterial stiffening and thickness in Type 2 diabetes. Diabet Med 2007;24(12):1329-35. doi:10.1111/j.14645491.2007.02278.x

50. Sergienko VA. Insulin resistance and arterial stiffness in patients with diabetes mellitus type 2 and cardiovascular autonomic neuropathy. Zh Nevrol Psikhiatr Im S S Korsakova 2014;114(4):11-5.

51. Ogawa O, Hayashi C, Nakaniwa T, Tanaka Y, Kawamori R. Arterial stiffness is associated with diabetic retinopathy in type 2 diabetes. Diabetes Res Clin Pract 2005;68(2):162-6. doi:10.1016/j.diabres.2004.09.008

52. Ogawa O, Hiraoka K, Watanabe T, Kinoshita J, Kawasumi M, Yoshi $\mathrm{H}$, Kawamori R. Diabetic retinopathy is associated with pulse wave velocity, not with the augmentation index of pulse waveform Cardiovasc Diabetol 2008;7:11. doi:10.1186/1475-2840-7-11

53. Mitchell GF. Increased aortic stiffness: an unfavorable cardiorenal connection. Hypertension 2004;43(2):151-3. doi:10.1161/01. HYP.0000114581.77705.29

54. Garnier A, Briet M. Arterial Stiffness and Chronic Kidney Disease. Pulse 2016:229-41. doi:10.1159/000443616

55. Briet $M$, Bozec $E$, Laurent $S$, Fassot $C$, London $G M$,Jacquot $C$, Froissart $M$, Houillier P, Boutouyrie P. Arterial stiffness and enlargement in mild-to-moderate chronic kidney disease. Kidney Int 2006;69(2):350 7. doi:10.1038/sj.ki.5000047

56. London GM, Blacher J, Pannier B, Guerin AP, Marchais SJ, Safar ME. Arterial wave reflections and survival in end-stage renal failure. Hypertension. 2001;38(3):434-8

57. Vlachopoulos C, Aznaouridis K, Stefanadis C. Clinical appraisal of arterial stiffness: the Argonauts in front of the Golden Fleece. Heart 2006:92(11):1544-50. doi:10.1136/hrt.2005.067025

58. Kullo IJ, Malik AR. Arterial ultrasonography and tonometry as adjuncts to cardiovascular risk stratification. J Am Coll Cardiol 2007;49(13):1413-26. doi:10.1016/j.jacc.2006.11.039

59. Mansia G, De Backer G, Dominiczak A, Cifkova R, Fagard R, Germano G, Grassi G, Heagerty AM, Kjeldsen SE, Laurent S, Narkiewicz K Ruilope L, Rynkiewicz A, Schmieder RE, Struijker Boudier HA Zanchetti A. 2007 ESH-ESC Guidelines for the management of arterial hypertension: the task force for the management of arterial hypertension of the European Society of Hypertension (ESH) and of the European Society of Cardiology (ESC). Blood Press 2007;16(3):135 232. doi:10.1080/08037050701461084

60. Mitchell GF. Arterial stiffness and wave reflection: biomarkers of cardiovascular risk. Artery Res 2009;3(2):56-64. doi:10.1016/j.artres.2009.02.002.Arterial

61. Guize L, Thomas F, Pannier B, Bean K, Jego B, Benetos A. All-cause mortality associated with specific combinations of the metabolic syndrome according to recent definitions. Diabetes Care 2007;30(9):2381-7. doi:10.2337/dc07-0186

62. Bjorntorp P. Metabolic implications of body fat distribution. Diabetes Care 1991;14(12):1132-43.

63. Longo R, Ricci C, Masutti F, Vidimari R, Croce LS, Bercich L, Tiribelli C, Dalla Palma L. Fatty infiltration of the liver. Quantification by $1 \mathrm{H}$ localized magnetic resonance spectroscopy and comparison with computed tomography. Invest Radiol 1993;28(4):297-302.

64. Egan BM, Lu G, Greene EL. Vascular effects of non-esterified fatty acids: implications for the cardiovascular risk factor cluster. Prostaglandins Leukot Essent Fatty Acids 1999;60(5-6):411-20.

65. Safar ME, Czernichow S, Blacher J. Obesity, arterial stiffness, and cardiovascular risk. J Am Soc Nephrol 2006;17(4 Suppl 2):S109-11. doi:10.1681/ASN.2005121321

66. Wohlfahrt P, Somers VK, Cifkova R, Filipovsky J, Seidlerova J, Krajcoviechova A, Sochor O, Kullo IJ, Lopez-Jimenez F. Relationship between measures of central and general adiposity with aortic stiffness in the general population. Atherosclerosis 2014;235(2):625-31. doi:10.1016/j.atherosclerosis.2014.05.958

67. Strasser B, Arvandi M, Pasha EP, Haley AP, Stanforth $P$, Tanaka H. Abdominal obesity is associated with arterial stiffness in middleaged adults. Nutr Metab Cardiovasc Dis 2015;25(5):495-502. doi:10.1016/j.numecd.2015.01.002

68. Arner P, Backdahl J, Hemmingsson P, Stenvinkel P, Eriksson-Hogling D, Naslund E, Thorell A, Andersson DP, Caidahl K, Ryden M. Regional variations in the relationship between arterial stiffness and adipocyte volume or number in obese subjects. Int J Obes (Lond) 2015;39(2):222-7. doi:10.1038/ijo.2014.118

69. Koumaras C, Tzimou M, Stavrinou E, Griva T, Gossios T, Katsiki N Athyros VG, Mikhailidis DP, Karagiannis A. Role of antihypertensive drugs in arterial "de-stiffening" and central pulsatile hemodynamics. Am J Cardiovasc Drugs 2012;12(3):143-56. doi:10.2165/11599040000000000-00000

70. Roman MJ, Devereux RB, Kizer JR, Devereux RB, Kizer JR, Lee ET, Galloway JM, Ali T, Umans JG, Howard BV. Central pressure more strongly relates to vascular disease and outcome than does brachial pressure: the Strong Heart Study. Hypertension 2007;50(1):197-203. doi:10.1161/HYPERTENSIONAHA.107.089078

71. Laurent S, Boutouyrie P, Asmar R, Gautier I, Laloux B, Guize L, Ducimetiere $P$, Benetos A.. Aortic stiffness is an independent predictor of all-cause and cardiovascular mortality in hypertensive patients. Hypertension 2001;37(5):1236-41.

72. Boutouyrie P, Tropeano Al, Asmar R, Gautier I, Benetos A, Lacolley $P$, Laurent $S$. Aortic stiffness is an independent predictor of primary coronary events in hypertensive patients: a longitudinal study. Hypertension 2002;39(1):10-5.

73. Wilkinson I, Cockcroft JR. Cholesterol, lipids and arterial stiffness. Adv Cardiol 2007;44:261-77. doi:10.1159/000096747

74. Wang X, Ye P, Cao R, Yang X, Xiao W, Thang Y, Bai Y, Wu H. Triglycerides are a predictive factor for arterial stiffness: a community-based 4.8 year prospective study. Lipids Health Dis 2016;15(1):97. doi:10.1186/ s12944-016-0266-8

75. Villela-Nogueira CA, Leite NC, Cardoso CRL, Salles GF. NAFLD and increased aortic stiffness: Parallel or common physiopathological mechanisms? Int J Mol Sci 2016;17(4). doi:10.3390/ijms17040460

76. Ferguson JM, Minas J, Siapantas S, Komesaroff PA, Sudhir K. Effects of a fixed-dose ACE inhibitor-diuretic combination on ambulatory blood pressure and arterial properties in isolated systolic hypertension. J Cardiovasc Pharmacol 2008;51(6):590-5. doi:10.1097/ FJC.0b013e31817a8316

77. Schneider MP, Delles C, Klingbeil AU, Ludwig M, Kolloch RE, Krekler $\mathrm{M}$, Stumpe KO, Schmieder RE. Effect of angiotensin receptor blockade on central haemodynamics in essential hypertension: results of a randomised trial. J Renin Angiotensin Aldosterone Syst 2008;9(1):49-56. doi:10.3317/jraas.2008.003

78. Ohira M, Endo K, Oyama T, Yamaguchi T, Ban N, Kawana H, Nagayama D, Nagumo A, Saiki A, Murano T, Watanabe H, Miyashita Y, Shirai K. Improvement of postprandial hyperglycemia and arterial stiffness upon switching from premixed human insulin 30/70 to biphasic insulin aspart 30/70. Metabolism 2011;60(1):78-85. doi:10.1016/j. metabol.2010.06.001

79. Stakos DA, Schuster DP, Sparks EA, Wooley CF, Osei K, Boudoulas $\mathrm{H}$. Long term cardiovascular effects of oral antidiabetic agents in non-diabetic patients with insulin resistance: double blind, prospective, randomised study. Heart 2005;91(5):589-94. doi:10.1136/ hrt.2003.027722

80. Kiyici S, Ersoy C, Kaderli A, Fazlioglu M, Budak F, Duran C, Gul OO, Sigirli D, Baran I, Tuncel E, Erturk E, Imamoglu S. Effect of rosiglitazone, metformin and medical nutrition treatment on arterial stiffness, serum MMP-9 and MCP-1 levels in drug naive type 2 diabetic patients. Diabetes Res Clin Pract 2009;86(1):44-50. doi:10.1016/j. diabres.2009.07.004

81. Shargorodsky M, Omelchenko E, Matas Z, Boaz M, Gavish D. Relation between augmentation index and adiponectin during one-year metformin treatment for nonalcoholic steatohepatosis: 
effects beyond glucose lowering? Cardiovasc Diabetol 2012;11:61. doi:10.1186/1475-2840-11-61

82. Agarwal N, Rice SPL, Bolusani H, Luzio SD, Dunseath G, Ludgate M Rees DA. Metformin reduces arterial stiffness and improves endothelial function in young women with polycystic ovary syndrome: a randomized, placebo-controlled, crossover trial. J Clin Endocrino Metab 2010;95(2):722-30. doi:10.1210/jc.2009-1985

83. Harashima K, Hayashi J, Miwa T, Tsunoda T. Long-term pioglitazone therapy improves arterial stiffness in patients with type 2 diabetes mellitus. Metabolism 2009;58(6):739-45. doi:10.1016/j.metabol.2008.09.015

84. Uzui H, Nakano A, Mitsuke Y, Geshi T, Sakata J, Sarazawa K, Morishita T, Satou T, Ishida K, Lee JD. Acarbose treatments improve arteria stiffness in patients with type 2 diabetes mellitus. J Diabetes Investig 2011;2(2):148-53. doi:10.1111/j.2040-1124.2010.00079.x

85. Nagayama D, Saiki A, Endo K, Yamaguchi T, Ban N, Kawana H, Ohira M, Oyama T, Miyashita Y, Shirai K. Improvement of cardio-ankle vascular index by glimepiride in type 2 diabetic patients. Int $\mathrm{J}$ Clin Pract 2010;64(13):1796-801. doi:10.1111/j.1742-1241.2010.02399.x

86. Duvnjak L, Blaslov K. Dipeptidyl peptidase-4 inhibitors improve arterial stiffness, blood pressure, lipid profile and inflammation parameters in patients with type 2 diabetes mellitus. Diabetol Metab Syndr 2016;8:26. doi:10.1186/s13098-016-0144-6

87. Zografou I, Sampanis C, Gkaliagkousi E, Iliadis F, Papageorgiou A Doukelis P, Vogiatzis K, Douma S. Effect of vildagliptin on hsCRP and arterial stiffness in patients with type 2 diabetes mellitus. Hormones (Athens) 2015;14(1):118-25. doi:10.14310/horm.2002.1512

88. Forst T, Michelson G, Ratter F, Weber MM, Anders S, Mitry M, Wilhelm $B$, Pfützner A. Addition of liraglutide in patients with Type 2 diabetes well controlled on metformin monotherapy improves several markers of vascular function. Diabet Med 2012;29(9):1115-8 doi:10.1111/ j.1464-5491.2012.03589.x

89. Cardiovascular Outcomes with Sodium-glucose Co-transporter 2 Inhibitors: A Review of the Clinical Evidence. Ottawa (ON): Canadian Agency for Drugs and Technologies in Health 2015 Nov 5.
90. Chilton R, Tikkanen I, Cannon CP, Crowe S, Woerle HJ, Broedl UC, Johansen OE. Effects of empagliflozin on blood pressure and markers of arterial stiffness and vascular resistance in patients with type 2 diabetes. Diabetes Obes Metab 2015;17(12):1180-93. doi:10.1111/ dom. 12572

91. Inzucchi SE, Zinman B, Wanner C, Ferrari R, Fitchett D, Hantel S, Espadero RM, Woerle HJ, BroedI UC, Johansen OE. SGLT-2 inhibitors and cardiovascular risk: proposed pathways and review of ongoing outcome trials. Diabetes Vasc Dis Res 2015;12(2):90-100. doi:10.1177/1479164114559852

92. Roman MJ, Devereux RB, Kizer JR, Okin PM, Lee ET, Wang W, Umans JG, Calhoun D, Howard BV. High central pulse pressure is independently associated with adverse cardiovascular outcome the strong heart study. J Am Coll Cardiol 2009;54(18):1730-4. doi:10.1016/j. jacc.2009.05.070

93. Wilkinson IB, Hall IR, MacCallum H, Mackenzie IS, McEniery CM, van der Arend BJ, Shu YE, MacKay LS, Webb DJ, Cockcroft JR. Pulsewave analysis: clinical evaluation of a noninvasive, widely applicable method for assessing endothelial function. Arterioscler Thromb Vasc Biol 2002;22(1):147-52.

94. Boutouyrie P, Lacolley P, Briet M, Regnault V, Stanton A, Laurent S, Mahmud A. Pharmacological modulation of arterial stiffness. Drugs 2011;71(13):1689-701. doi:10.2165/11593790-000000000-00000

95. Williams B, Lacy PS, Thom SM, Cruickshank K, Stanton A, Collier D, Hughes $A D$, Thurston $H, O$ 'Rourke M; CAFE Investigators; AngloScandinavian Cardiac Outcomes Trial Investigators; CAFE Steering Committee and Writing Committee. Differential impact of blood pressure-lowering drugs on central aortic pressure and clinical outcomes: principal results of the Conduit Artery Function Evaluation (CAFE) study. Circulation 2006;113(9):1213-25. doi:10.1161/ CIRCULATIONAHA.105.595496

96. Oliver JJ, Webb DJ. Noninvasive Assessment of Arterial Stiffness and Risk of Atherosclerotic Events. Arterioscler Thromb Vasc Biol 2003; 23(4):554-66. 